\title{
Short Communication: A small-scale coprological survey of the endoparasites in the Himalayan goral Naemorhedus goral (Hardwick, 1825) in Nepal
}

\author{
JAGAN NATH ADHIKARI ${ }^{1,2}$, ROSHAN BABU ADHIKARI ${ }^{3,4}$, BISHNU PRASAD BHATTARAI $^{1}$, \\ TEJ BAHADUR THAPA ${ }^{1}$, TIRTH RAJ GHIMIRE ${ }^{3, \bullet}$ \\ ${ }^{1}$ Central Department of Zoology, Institute of Science and Technology, Tribhuvan University. Kirtipur, Kathmandu, Nepal \\ ${ }^{2}$ Department of Zoology, Birendra Multiple Campus, Tribhuvan University. Bharatpur, Chitwan, Nepal \\ ${ }^{3}$ Animal Research Laboratory, Faculty of Science, Nepal Academy of Science and Technology. Khumaltar, Lalitpur, Nepal. Tel.: +977-1-5547715. \\ "email: tirthprimate@gmail.com \\ ${ }^{4}$ Third Pole Conservancy. Bhaktapur, Nepal
}

Manuscript received: 2 January 2020. Revision accepted: 14 February 2021.

\begin{abstract}
Adhikari JN, Adhikari RB, Bhattarai BP, Thapa TB, Ghimire TR. 2021. Short Communication: A small-scale coprological survey of the endoparasites in the Himalayan goral Naemorhedus goral (Hardwick, 1825) in Nepal. Biodiversitas 22: 1285-1290. This study was carried out to detect the various endoparasites in the fecal samples of the Himalayan goral Naemorhedus goral (Hardwicke, 1825) from a forest patch of Rumsi area, the Seti River basin, Tanahun district, Nepal. Importantly, 17 fecal samples (89.5\%) were positive for different parasites. Their positive rates showed the following orders as Strongyle (73.7\%), Entamoeba sp. (52.6\%), Strongyloides sp. (52.6\%), Cryptosporidium sp. (26.3\%), Cyclospora sp. (26.3\%), Eimeria sp. (10.5\%), Mullerius capillaris (10.5\%), and Blastocystis sp. (5.3\%). These results showed the prevalence status of the endoparasites in the Himalayan goral. This study provides general knowledge about the parasitic community using a non-invasive method. This is the first work in Himalayan goral of Nepal, hence intensive study to the other parts of Nepal is recommended.
\end{abstract}

Keywords: Coccidia, gastrointestinal parasites, Himalayan goral, fecal pellets, strongyles

\section{INTRODUCTION}

The Himalayan goral Naemorhedus goral (Hardwicke, 1825) (Order: Artiodactyla; Family: Bovidae; Subfamily: Caprinae) is listed as Near Threatened on the International Union for Conservation of Nature (IUCN) Red List globally and nationally (Amin et al. 2018, IUCN 2019) and Appendix $\mathrm{I}$ in Convention on International Trade in Endangered Species of Wild Fauna and Flora (CITES) category (CITES 2020). N. goral, a medium-sized mammal, is endemic to the mountains of central East Asia including Nepal, Bhutan, China (south Tibet), Northern India including Sikkim, and Northern Pakistan with a normal distribution range from 900 to $4,000 \mathrm{~m}$ above sea level (asl) (IUCN 2019). In Nepal, Himalayan goral are widely distributed species on the forested slopes up to the timberline (Wegge and Oli 1997). The species inhabits steep mountainous areas and sometimes use evergreen forests near cliffs, but primarily stays within rugged rocky terrain. They feed on grass round in the ridges and steep rocky slopes, and hide in forest or rock crevices (Wegge and Oli 1997, Ashraf et al. 2016). In Nepal, goral occurs in nine National Parks: Khaptad, Rara, Langtang, MakaluBarun, Bardia, Chitwan, Sagarmatha, Parsa and SheyPhoksundo (Wegge and Oli 1997, DNPWC 2020), as well as within the Annapurna Conservation Area, Dhorpatan Hunting Reserve, Kanchenjunga Conservation Area, Gaurishankhar Conservation Area, Manaslu Conservation
Area and Appi-Nampa Conservation Area (2020). Besides the national parks and conservation areas, they are also found in mountain terrains of midhill human-dominated landscape of Nepal (Adhikari et al. 2019) but there is very low exploration (Adhikari et al. 2019) and the status of Himalayan goral is even unknown.

In these regions, the mature individuals of this species are continuing to decline (IUCN 2019). Notably, in different areas, the declining factors or the threats to its survival are different, for example, hunting, overgrazing, poaching, habitat destruction, disturbance, and competition with livestock (IUCN 2019). Besides, different diseases like pneumonia, gastroenteritis, hepatitis, and parasitosis have been implicated in the deaths of $N$. goral in many areas in India (Rathore and Khera 1982). In Pakistan, overhunting, natural disasters, predators, parasites, and diseases have been indicated to be their populations' declining factors (Perveen et al. 2013). Interestingly, how microspecies like viruses, bacteria, fungi, and parasites lead to the endangerment of various macrofauna like humans and animals in the Hindu-Kush Himalayan regions has been extensively reviewed before (Ghimire et al. 2020). Among microspecies, parasites can negatively affect distribution, occupancy, body structure, pregnancy rate, offspring survival, and offspring size of wild ungulates in the mountain (Aleuy et al. 2020). We and other researchers of Nepal, already focused on the study of prevalence of gastrointestinal parasites in wild animals with the help of 
fecal examination viz- Lama et al. (2015), Bista et al. (2017) in red panda, Adhikari et al. (2020) in bat, Achhami et al. (2016) in musk deer, Adhikari and Dhakal (2018), Sapkota et al. (2020) in rhesus monkeys, and Gupta (2017) in wild buffalo. These studies have clearly mentioned the endoparasites in these animals and have questioned the impact on their health.

Most of the researchers of Nepal focused on the population status, habitats and threats to - gorals (Adhikari et al. 2019). However, studies related to endoparasites in gorals have been lacking. Therefore, the current study aimed to record the endoparasites in the gorals' fecal samples in a forest patch of Rumsi area located in the Seti River basin, Tanahun district, Nepal which is the representative part of the midhill human-dominated landscape.

\section{MATERIALS AND METHODS}

\section{Study area}

The study was conducted in the Rumsi area $\left(27^{\circ} 55^{\prime} 08.12^{\prime \prime} \mathrm{N} / 84^{\circ} 18^{\prime} 35.32^{\prime \prime} \mathrm{E}\right.$ to $27^{\circ} 55^{\prime} 11.36^{\prime}$ ', N/84'19'18.83'E, Elevation ranges: 525-1421 m asl) of Seti River basin of Tanahun district in western Nepal (Figure 1). The area has a steep and gentle slope and a dense mixed forest with grasses like Eulaliopsis binate,
Imperata cylindrica, Saccharum spontaneum, Cynodon dactylon, Phoenix humilis, Eleusine indica, Digitaria ciliaris, and Smilax ovalifolia (Figure 2). The forest contained trees like Shorea robusta, Adina cordifolia, Terminalia alata, Schima wallichii, Castanopsis indica, Quercus sp., and Michelia excels. Steep and rugged rocky terrain of area of Rumsi supports the habitat of Himalayan gorals. This small patch of the forest is surrounded by the villages named Rumsi, Keshabtar, Harkapur, Nayagaun, Nagdi, Thulo Kharka, and Majgaun. The local people depended on agriculture and animal husbandry. Their livestock included goats, sheep, cattle, and buffaloes that were usually taken to the forest for grazing.

\section{Study design, sample collection, and sample examination}

The study was a cross-sectional descriptive type. Based on the direct observation site, we collected the fresh fecal pellets of goral from April 2019 to May 2019. Fecal pellets were mainly opportunistically collected from the steep landscapes (range: 525-1410m asl). Usually, each goral defecated in one place. In an area of $20 \times 20$-centimeter squares, one fecal pellet group of goral consisted of 134 to 230 rolling to large-sized solid pellets (Figure 3). The samples were put in sterile vials containing $2.5 \%$ potassium dichromate solution and were transported to the laboratory.

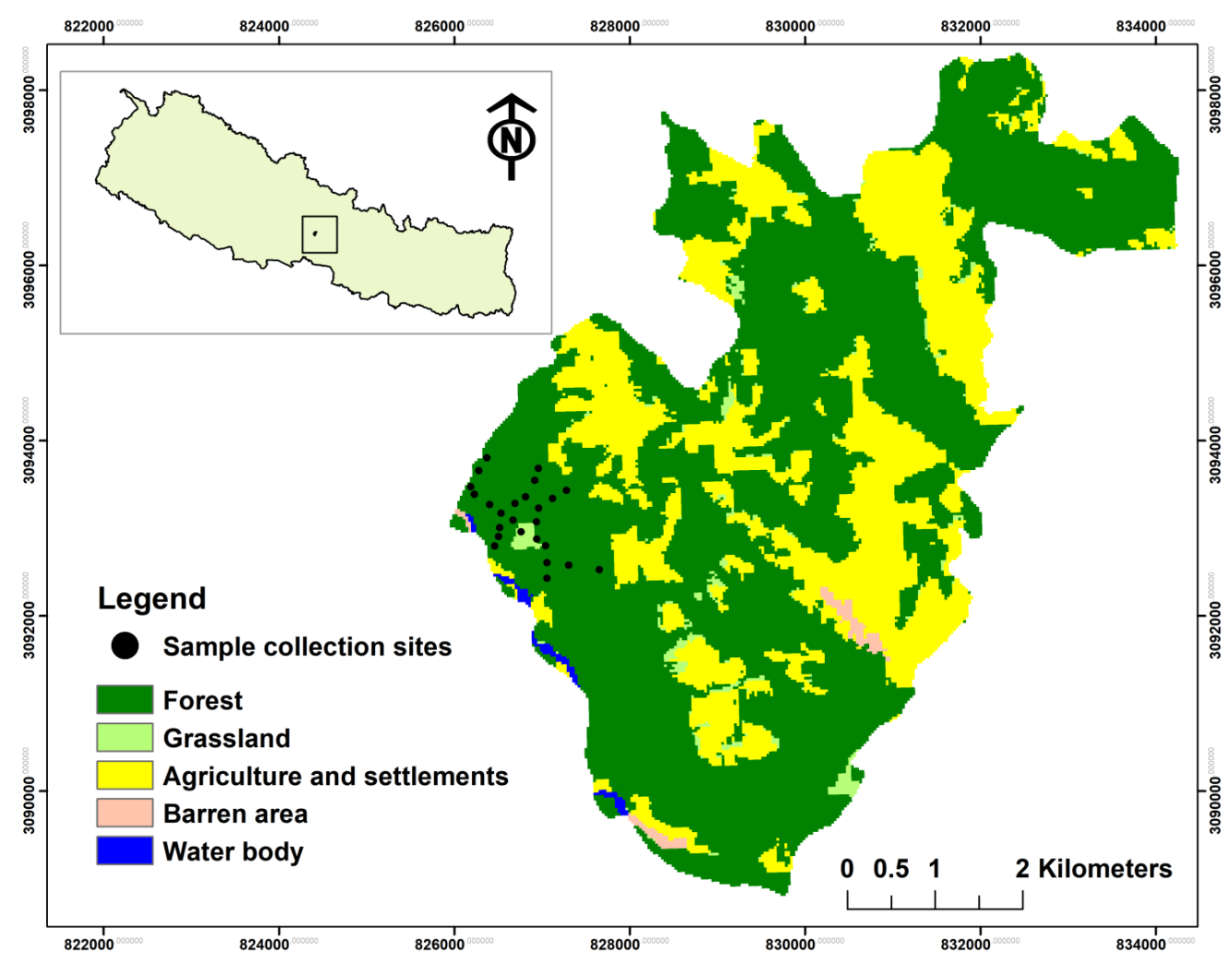

Figure 1. Study area in Seti River basin of Tanahun District in western Nepal 


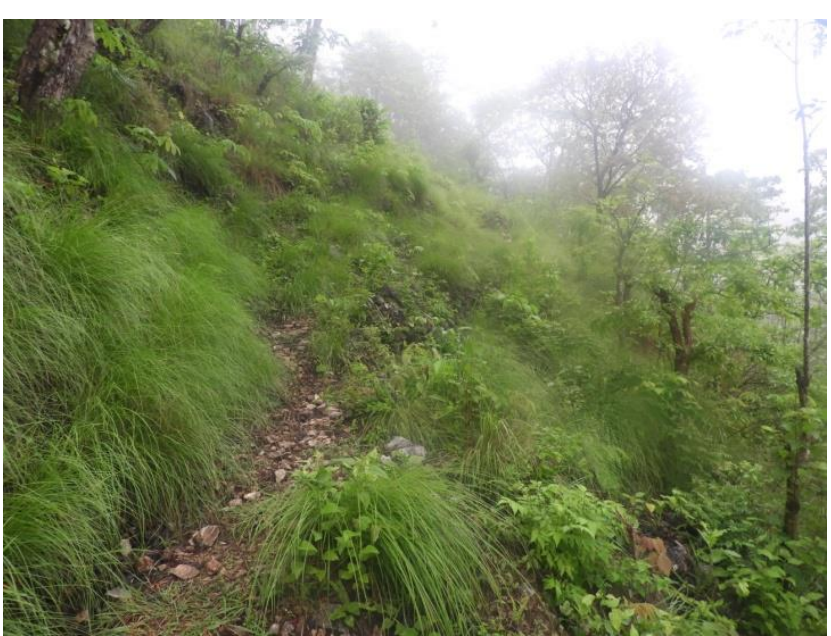

Figure 2. Landscapes of the study area.

The laboratory techniques of processing and examining endoparasites in the fecal samples explained previously were applied (Romero-Castañón et al. 2008, Ghimire and Bhattarai 2019, Adhikari et al. 2020). About two grams (g) of fecal samples were taken and filtered in a tube. The fecal filtrate was directly examined at $2.5 \%$ potassium dichromate, $0.9 \%$ saline solution, and Lugol's iodine. The fecal filtrate was centrifuged at concentrated $\mathrm{NaCl}$ $(45 \% \mathrm{w} / \mathrm{v})$ at 1200 revolution per minute, rpm x 5 minutes via floatation techniques to observe helminth eggs and coccidian oocysts (e.g., Eimeria). Similarly, 1 milliliter (ml) of filtrate and $13 \mathrm{ml}$ of $0.9 \% \mathrm{NaCl}$ were mixed in a 15 $\mathrm{ml}$ centrifuge tube, and the mixture was centrifuged (1200 rpm x 5 minutes) for sedimentation technique. The sediment was put on a glass slide containing Lugol's iodine. All samples were observed under the light microscope (Optika Microscopes Italy, B-383PLi) at a total magnification of $\mathrm{x} 100$ and $\mathrm{x} 400$.

Coccidia-positive samples were proved using modified acid-fast staining techniques. Thus, about two to five grams of samples were centrifuged $(1200 \mathrm{rpm} \times 5$ minutes $)$ at $10 \%$ formal ether solution. The sediment's thin smear was prepared in a slide that was allowed to dry at room temperature. It was then fixed with absolute methanol (2 minutes), stained with carbol fuchsin (10 minutes), washed with distilled water, and decolorized by acid alcohol for 2 minutes. It was counterstained with malachite green (1 minute), rinsed with distilled water, and was allowed to dry. The slide was observed at x1000 magnification using immersion oil in a compound microscope. Images of the cysts, oocysts, eggs, and larval stages were measured using ImageJ (National Institute of Health, USA) and were identified using works of literature (https://parasitology.cvm.ncsu.edu/m_keys/ruminant/parasi te/strongyle.html, accessed on August 15, 2019) (RomeroCastañón et al. 2008, Ghimire and Bhattarai 2019).

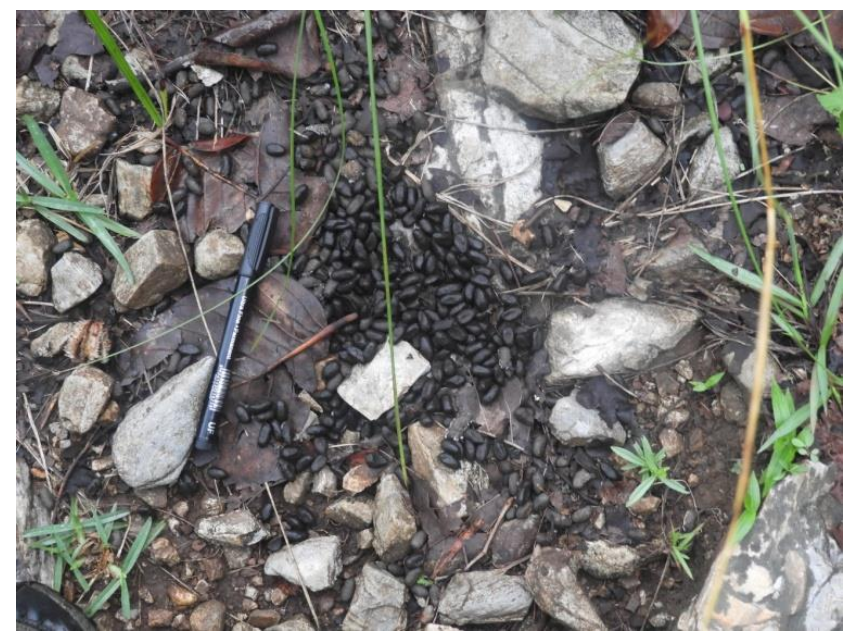

Figure 3. Fecal pellets of the Himalayan goral

\section{RESULTS AND DISCUSSION}

We recorded a total of 34 individuals of $N$. goral in the field (Figure 4). Only 19 fresh fecal samples were found and collected for laboratory investigations.

This is the first report of the prevalence and parasitic richness study of GI parasites in Himalayan gorals in Nepal. In this study, the prevalence $(89.5 \%)$ of GI parasites was higher than that reported in Pakistan (75\%); however, the current diversity of parasites was lower compared to those in gorals of this country (Rana et al. 2015). We recorded five protozoa like Blastocystis sp., Cryptosporidium sp., Eimeria sp., Cyclospora sp., Entamoeba sp., and three helminths like Mullerius capillaris, strongyle, and Strongyloides sp. (Table 1) (Figure 5).

Table 1. Gastrointestinal parasites in the Himalayan goral, Naemorhedus goral (Hardwicke, 1825) in Rumsi area, Tanahun, Nepal

\begin{tabular}{lc}
\hline \multicolumn{1}{c}{ Parasites } & \% positive $(\mathbf{N}=\mathbf{1 9})$ \\
\hline Strongyle & $73.7 \%$ \\
Entamoeba sp. & $52.6 \%$ \\
Strongyloides $\mathrm{sp}$. & $52.6 \%$ \\
Cryptosporidium sp. & $26.3 \%$ \\
Cyclospora sp. & $26.3 \%$ \\
Eimeria sp. & $10.5 \%$ \\
Muellerius capillaris & $10.5 \%$ \\
Blastocystis sp. & $5.3 \%$ \\
Duplet infections & $42.1 \%$ \\
Triplet infections & $26.3 \%$ \\
Quadruplet infections & $10.5 \%$ \\
Pentuplet infections & $10.5 \%$ \\
Total & $89.5 \%$ \\
\hline
\end{tabular}




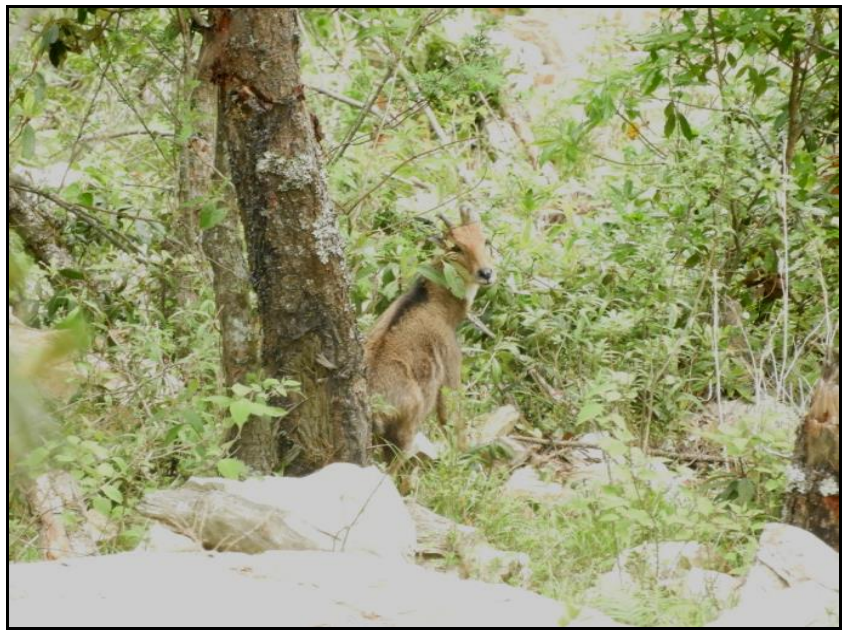

Figure 4. Himalayan goral

Compared to this, in Pakistan, parasites like Fasciola hepatica, Thysaniezia spp., Moniezia expansa, Nematodirus spathiger, Gaigeria pachyscelis, Trichostrongylus spp., Haemonchus contortus, Bunostomum trigonocephalum, Cotylophoron cotylophorum, Fascioloides magna, and Ostertagia circumcincta have been reported in the goral (Rana et al.
2015). Blastocystis species is predominantly reported in many wild and domestic animals including gorals worldwide (Deng et al. 2019). The current prevalence rate $(5.3 \%)$ of Blastocystis in gorals was lower than reported from China (18.2\%) (Cai et al. 2009). Entamoeba sp., Cryptosporidium sp., and Cyclospora sp. were firstly reported protozoa in gorals. Although pathogenic in humans and others, the role of Entamoeba sp. in goral is not known. Cryptosporidium sp. and Cyclospora sp. are obligate intracellular apicomplexan parasites that inhabit in the epithelium of the intestine or bile duct of various vertebrates and invertebrates (Duszynski and Upton 2001). Both Cryptosporidium sp. and Cyclospora sp. are eimeriid parasites that are water-, soil-, food-, and fecal-borne in nature. Both parasites may lead to asymptomatic as well as symptomatic illnesses in humans and several animals, however, we do not know their pathogenicity in the gorals.

Different Eimeria species have previously been reported from $N$. goral (Moudgil et al. 2020), N. crispus (Japanese serow), and N. swinhoei (Formosan serow) (Inoue and Imura 1991) in which they might cause coccidiosis. The role of Eimeria species cannot be neglected because the death of one newborn goral between 1976 and 1999 was linked to coccidiosis at Everland Zoological Gardens (Shin et al. 2000).
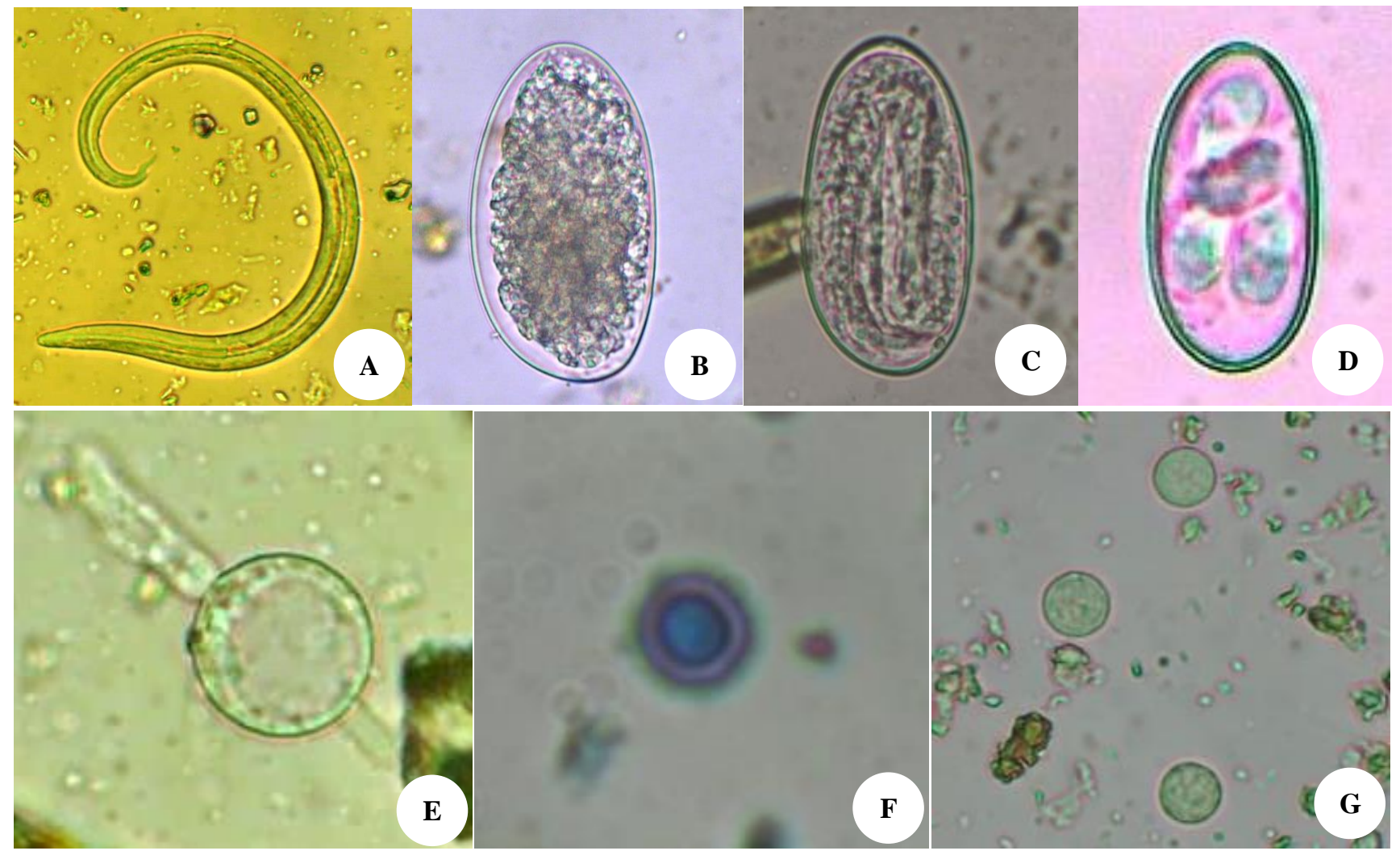

Figure 5. Endoparasites of the Himalayan gorals; A. Larva of Muellerius capillaris at potassium dichromate solution $(268 \times 12 \mu \mathrm{m}$, at $400 x)$, B. Egg of strongylid at direct mount $(97 \times 54 \mu \mathrm{m}$, at $400 \mathrm{x}), \mathrm{C}$. Egg with larva of Strongyloides sp. at Iodine staining $(55 \times 19 \mu \mathrm{m}$, at 400x), D. Oocyst of Eimeria sp. after floatation $(26 \times 14 \mu \mathrm{m}$, at 400x), e. Cyst of Blastocystis sp. at Iodine staining $(19 \times 17 \mu \mathrm{m}$, at $400 \mathrm{x})$, F. Oocyst of Cryptosporidium sp. after acid-fast staining $(4 \times 4 \mu \mathrm{m}$, at $1000 \mathrm{x})$ shown by arrow, G. Cysts of Entamoeba spp. at Iodine staining $(8 \times 8 \mu \mathrm{m}$, at $400 \mathrm{x})$ indicated by arrows 
Strongyle species include many nematodes like Bunostomum, Haemonchus, Nematodirus, Ostertagia, Trichostrongylus, and others. Unless we do the culture of these parasites, it is not easy to identify up to the genera level; that is why we have categorized them into 'strongyle' based on the egg morphology. The presence of strongyle in $N$. goral has already been reported from Pakistan and India (Rana et al. 2015). It was critical that the deaths of 18 gorals were reported all over India from 1975 to 1977 , and in these cases, one death was due to helminthic infestation; other deaths were attributed to pneumonia, gastroenteritis, hepatitis, and others (Rathore and Khera 1982). Similarly, 10 N. goral sent from the Sudzuklinsk State Preserve to the Moscow Zoological Gardens died from helminth infections. These animals had been diagnosed with 27 helminths including, strongyle (Shults and Kadenatsii 1950), indicating the latter to be critical in goral's health. It is believed that host-parasite relationship is dynamic. Thus, particular species of parasites usually live in equilibrium with their host. In this context, both parasite and host must adapt to keep up with each other's adaptations (Morand and Krasnov 2010). However, under certain situations, for example, during stress, presence of other parasites and pathogens, the balance can be disturbed. This is evidenced by the enhanced pathology in the hosts when there are multiple infections of the parasites. Environmental stress by pollutants, habitat alterations, and introduced species have been shown to affect the impacts of parasites (Lafferty and Kuris 1999). In the current study, all positive samples had mixed infections of two or more than two parasites (Table 1). The prevalence rates of samples positive for duplet, triplet, quadruplet, and pentuplet parasitic infections were $42.1 \%, 26.3 \%, 10.5 \%$, and $10.5 \%$, respectively. It is not easy to explain the complex situations created by mixed infections because the interactions among various parasite species may lead to positive, negative, or null effects (Hoarau et al. 2020). Thus, studies involving all pathogen communities should be conducted to assess the impacts on goral.

The current study found Strongyloides sp. with a prevalence rate of $52.6 \%$. The significance of this species cannot be ignored in gorals because it can lead to severe infections, including dehydration, anorexia, and anemia in similar hosts like goats (Pienaar et al. 1999), however, pathogenicity may depend on the intensity of the parasite/s. Although we did not use the McMaster techniques to quantify the parasitic species, our study may reflect the result of high mixed infection. The larva of Mullerius capillaris has been detected at a prevalence rate of $10.5 \%$. This nematode infects the lungs, and its larva is released via sputum and stool. It is transmitted by consuming secondary hosts like slugs or snails that occurs accidentally in goats and sheep (López and Martinson 2017).

In this study, all positive samples had mixed infections of two or more than two parasites (Table 1). The prevalence rates of samples positive for duplet, triplet, quadruplet, and pentuplet parasitic infections were $42.1 \%$, $26.3 \%, 10.5 \%$, and $10.5 \%$, respectively. It is not easy to explain the complex situations created by mixed infections because the interactions among various parasite species may lead to positive, negative, or null effects (Hoarau et al. 2020). Thus, studies involving all pathogen communities should be conducted to assess the impacts on goral.

While the diversity and prevalence of the endoparasites are large in gorals, the underlying causes are not fully understood. Several hypotheses may occur. Firstly, the feeding behavior of the gorals may play in increased parasitosis. Gorals are both browsers and grazers (Chaiyarat et al. 1999). therefore, the transmission of these pathogens is probable via ingestion of larva or cyst or oocysts stages or larva-infected secondary hosts like slugs and snails along with grasses. Secondly, feral goats, dogs, and domestic and wild animals might play critical roles in parasite transmission in the study area. The fecal samples of these animals have already been reported to carry GI parasites similar to our current study (Lama et al. 2015, Ghimire and Bhattarai 2019, Adhikari et al. 2020, Sapkota et al. 2020). Importantly, cross-transmission of parasites via the contact with fecally-contaminated feces of domestic animals brought for grazing or interacting livestock may occur in the place. In these scenarios, both competitions, as well as sharing, may occur. For example, potential competition occurs between goral and other ungulates like domestic cattle, Northern red muntjac (Muntiacus vaginalis), and Himalayan serow (Capricornis thar) for living space, escape cover, water sources, salt licks, and forage species (Chaiyarat et al. 1999). Besides, many of these parasites are also reported in the GI tract of humans and several wild and domestic animals. It may reflect the possibility of cross-transmission of the parasites during the close-contact of the gorals with those of humans and other domestic and wild animals. In the same way, the competition of vegetation occurs with those of hill goats (Bhattacharya et al. 2012). In both cases, the likelihood of acquiring parasites by gorals is enhanced. Finally, the possibility of goral to act as a natural host of those parasites cannot be ignored. Gorals, goats, and sheep belong to the subfamily Caprinae and can have similar types of endoparasites.

The current study explores the diversity and prevalence of endoparasites in the gorals. It also highlights how closecontact with feral domestic animals and wildlife may lead to enhanced parasite transmission in gorals. Therefore, it may partly contribute to the decision-making process and formulating policy for the management of gorals in a small area.

\section{ACKNOWLEDGEMENTS}

Our special thanks go to the Division Forest Office, Tanahun for the permission (Permission Number: 7492074/075), all the members of Rumsi Community Forest and Chandraman Thapa, the Former Chairman of Rumsi Community Forest for their kind help and support during fieldwork, Nepal Academy of Science and Technology (NAST) for providing the laboratory facility. 


\section{REFERENCES}

Achhami B, Sharma HP, Bam AB. 2016. Gastro intestinal parasites of Musk Deer (Moschus chrysogaster Hodgson, 1839) in Langtang national park, Nepal. J Inst Sci Technol 21: 71-75. DOI: 10.3126/jist.v21i1.16053.

Adhikari JN, Bhattarai BP, Thapa TB. 2019. Determinants of distribution of large mammals in Seti River basin, Tanahun district of western Nepal. J Inst Sci Technol 24: 63-71. DOI: 10.3126/jist.v24i1.24638.

Adhikari PP, Dhakal P. 2018. Prevalence of gastro-intestinal parasites of Rhesus macaque (Macaca mulatta Zimmermann, 1780) and hanuman langur (Semnopithecus entellus Dufresne, 1797) in Devghat, Chitwan, Nepal. J Inst Sci Technol 22: 12-18. DOI: 10.3126/jist.v22i2.19590.

Adhikari RB, Maharjan M, Ghimire TR. 2020. Prevalence of Gastrointestinal Parasites in the Frugivorous and the Insectivorous Bats in Southcentral Nepal. J Parasitol Res. DOI: $10.1155 / 2020 / 8880033$.

Aleuy OA, Serrano E, Ruckstuhl KE, Hoberg EP, Kutz S. 2020. parasite intensity drives fetal development and sex allocation in a wild ungulate. Sci Rep 10: 1-10. DOI: 10.1038/s41598-020-72376-x.

Amin R, Baral HS, Lamichhane BR, Poudyal LP, Lee S, Jnawali SR et al. 2018. The status of Nepal's mammals. J Threatened Taxa 10: 1136111378. DOI: 10.11609/jott.3712.10.3.11361-11378.

Ashraf N, Anwar M, Hussain I, Mirza SN, Latham MC, Latham ADM 2016. Habitat use of Himalayan grey goral in relation to livestock grazing in Machiara National Park, Pakistan. Mammalia 80: 59-70.

Bhattacharya T, Kittur S, Sathyakumar S, Rawat G. 2012. Diet overlap between wild ungulates and domestic livestock in the greater Himalaya: implications for management of grazing practices. In: Proceedings of the Zoological Society. Springer.

Bista D, Shrestha S, Kunwar AJ, Acharya S, Jnawali SR, Acharya KP. 2017. Status of gastrointestinal parasites in Red Panda of Nepal. PeerJ 5: e3767. DOI: $10.7717 /$ peerj.3767.

Cai J, Qiao J, Zhang X, Jin X, Ren J, Ma Q et al. 2009. Observation on intestinal parasitic morphology and infection in captive rare wildlife in Shaanxi Province. Chinese J Zool 44: 63-69.

Chaiyarat R, Laohajinda W, Kutintara U, Nabhitabhata J. 1999. Ecology of the goral (Naemorhedus goral) in Omkoi Wildlife Sanctuary Thailand. Nat Hist Bull Siam Society 47: 191-205.

CITES. 2020. Appendices The Convention on International Trade in Endangered Species of Wild Fauna and Flora. https://www.cites.org/eng/app/appendices.php.

Deng L, Chai Y, Zhou Z, Liu H, Zhong Z, Hu Y et al. 2019 Epidemiology of Blastocystis sp. infection in China: a systematic review. Parasite (Paris, France) 26: 41-41. DOI: 10.1051/parasite/2019042.

DNPWC. 2020. National Parks of Nepal. Department of National Parks and Wildlife Conservation Nepal. http://www.dnpwc.gov.np/en/

Duszynski DW, Upton SJ. 2001. Cyclospora, Eimeria, Isospora and Cryptosporidium spp. Parasitic diseases of wild mammals 2: 430-442.

Ghimire TR, Bhattarai N. 2019. A survey of gastrointestinal parasites of goats in a goat market in Kathmandu, Nepal. J Parasitic Diseases 43: 686-695. DOI: 10.1007/s12639-019-01148-w.

Ghimire TR, Regmi GR, Huettmann F. 2020. When micro drives the macro: A fresh look at disease and its massive contributions in the Hindu Kush-Himalaya. In Hindu Kush-Himalaya Watersheds Downhill: Landscape Ecology and Conservation Perspectives. Springer, Cham. DOI: 10.1007/978-3-030-36275-1_40.
Gupta S. 2017. Prevalence of Intestinal Parasites in Wild Buffalo (Bubalus arnee, Kerr, 1792) of Koshi Tappu Wildlife Reserve, Nepal. Central Department of Zoology Institute of Science and Technology Tribhuvan University, Kathmandu, Nepal.

Hoarau AO, Mavingui P, Lebarbenchon C. 2020. Coinfections in wildlife: Focus on a neglected aspect of infectious disease epidemiology. PLoS Pathogens 16: e1008790. DOI: 10.1371/journal.ppat.1008790.g001.

Inoue I, Imura M. 1991. Eimeria gozaishoensis n. sp. from the Formosan serow (Capricornis crispus swinhoei). J Wildlife Dis 27: 214-216.

IUCN. 2019. The IUCN Red List of Threatened Species. Himalayan Goral: Naemorhedus goral. International Union for Conservation of Nature and Natural Resources (IUCN). https://www.iucnredlist.org/

Lafferty KD, Kuris AM. 1999. How environmental stress affects the impacts of parasites. Limnol Oceanogr 44 (3part2): 925-931.

Lama ST, Lama RP, Regmi GR, Ghimire TR. 2015. Prevalence of intestinal parasitic infections in free-ranging Red Panda Ailurus fulgens Cuvier, 1825 (Mammalia: Carnivora: Ailuridae) in Nepal. J Threatened Taxa 7: 7460-7464. DOI: 10.11609/JoTT.o4208.7460-4.

López A, Martinson SA. 2017. Chapter 9 - Respiratory System, Mediastinum, and Pleurae1. In: Zachary JF (ed.). Pathologic Basis of Veterinary Disease. $6^{\text {th }}$ ed. Mosby-Elsevier, St. Louis, MO.

Moudgil AD, Singla LD, Singh M. 2020. Seasonal coprological survey for assessment of risk factors associated with gastrointestinal parasitism in zoo-housed animals of Punjab, India. Biol Rhythm Res 51: 1273-1287. DOI: 10.1080/09291016.2019.1571706

Perveen F, Khan A, Shah AH. 2013. Hunting and Trapping Pressures on the Himalayan Goral, Naemorhedus goral (Hardwicke) (Artiodactyla: Bovidae) in Kohistan, Pakistan. Am J Zool Res 1: 5-11.

Pienaar J, Basson P, Du Plessis J, Collins HM, Naude T, Boyazoglu P et al. 1999. Experimental studies with Strongyloides papillosus in goats. http://hdl.handle.net/2263/20085.

Rana MA, Ahmad I, Jabeen F, Naureen A, Munaza S. 2015. Comparative study of endo-parasites from fecal samples of sambar (Rusa unicolor) and goral (Naemorhedus goral) in captivity. J Biodiv Environ Sci 6: 399-408.

Rathore BS, Khera SS. 1982. Causes of mortality in mammals of Bovidae family in captivity and free living state in India. J Bombay Nat Hist Soc 79: 190-193.

Romero-Castañón S, Ferguson BG, Güiris D, González D, López S, Paredes A et al. 2008. Comparative parasitology of wild and domestic ungulates in the Selva Lacandona, Chiapas, Mexico. Compar Parasitol 75: 115-127. DOI: 10.1654/4267.1.

Sapkota B, Adhikari RB, Regmi GR, Bhattarai BP, Ghimire TR. 2020. Diversity and prevalence of gut parasites in urban macaques. Appl Sci Technol Ann 1: 34-41. DOI: 10.3126/asta.v1i1.30270.

Shin N, Kwon S, Lee G, Kim Y, Kweon O, Kim D. 2000. Retrospective survey on the mortality of gorals at Everland Zoological Gardens (1976-1999). Korean J Vet Clin Med 17: 515-518.

Shults RS, Kadenatsii AN. 1950. Helminths of Nemorhaedus goral in the Far East. Trudy Gel'mintologicheskoi Laboratorii. Akademiya Nauk SSSR 3: 152-160.

Wegge P, Oli MK. 1997. Nepal. In: Shackleton DM (eds.). Wild Sheep and Goats and Their Relatives: Status Survey and Conservation Action Plan for Caprinae. IUCN/SSC Caprinae Specialist Group, Gland, UK and Cambridge, UK., Gland, UK and Cambridge, UK. 